\title{
A política afirmativa "Argumento de Inclusão" como forma de acesso à universidade pública: 0 caso da Universidade Federal do Rio Grande do Norte
}

\author{
Almog Griner \\ Universidade Federal do Rio Grande do Sul (UFRGS) / Programa de Pós-graduação em \\ Administração (PPGA) \\ Porto Alegre / RS - Brasil \\ Luciano Menezes Bezerra Sampaio \\ Universidade Federal do Rio Grande do Norte (UFRN) / Programa de Pós-graduação em \\ Administração (PPGA) \\ Natal / RN - Brasil \\ Raquel Menezes Bezerra Sampaio \\ Universidade Federal do Rio Grande do Norte (UFRN) / Escola de Ciência e Tecnologia \\ Natal / RN - Brasil
}

\begin{abstract}
Antes da aprovação da Lei $\mathrm{n}^{\mathrm{o}}$ 12.711/2012, que institui constitucionalmente a reserva de vagas nas universidades federais, modelos de inclusão foram amplamente discutidos e aplicados em diferentes instituições públicas de ensino superior. A pesquisa aqui exposta analisa e discute o Argumento de Inclusão (AI) - política de ação afirmativa que fornece pontuação adicional aos alunos provenientes de escolas públicas - existente na Universidade Federal do Rio Grande do Norte (UFRN) entre os anos de 2006-12. A partir de uma ampla base de dados, foi usada a técnica dos Mínimos Quadrados Ordinários (MQO) e uma Regressão Quantílica considerando como controles as variáveis das características pessoais, socioeconômicas e escolares dos candidatos ao Vestibular 2010 da UFRN. Os resultados mostram a relevância do sistema de pontuação adicional como incentivo para o acesso inclusivo ao ensino superior, e apontam novas evidências acerca de variáveis que afetam positiva e negativamente este acesso.
\end{abstract}

Palavras-chave: ações afirmativas; acesso à universidade; Argumento de Inclusão (AI); políticas públicas; determinantes de desempenho.

DOI: http://dx.doi.org/10.1590/0034-7612123593

Artigo recebido em 10 set. 2013 e aceito em 29 abr. 2015. 
La política afirmativa "Argumento de Inclusión" como una forma de acceso a la universidad pública: el caso de la Universidade Federal do Rio Grande do Norte

Antes de la aprobación de la Ley no 12.711/2012 que instituye constitucionalmente la reserva de cupos en las universidades federales, los modelos de inclusión fueron ampliamente discutidos y aplicados en diferentes instituciones públicas de enseñanza superior. El trabajo aquí expuesto analiza y discute el Argumento de Inclusión (AI) - política de acción afirmativa que otorgaba un puntaje adicional a los alumnos provenientes de escuelas públicas - existente en la Universidade Federal do Rio Grande do Norte (UFRN) entre los años 2006-12. A partir de una amplia base de datos, fue utilizada la técnica de los Mínimos Cuadrados Ordinarios (MCO) y una Regresión Cuartílica considerando como control las variables de las características personales, socioeconómicas y escolares de los candidatos del examen de ingreso del año 2010 en la UFRN. Los resultados muestran la relevancia del sistema de puntaje adicional como incentivo para el acceso inclusivo a la enseñanza superior y apuntan nuevas evidencias acerca de las variables que afectan positiva y negativamente a este acceso.

Palabras clave: acciones afirmativas; acceso a la universidad; Argumento de Inclusión (AI); políticas públicas; determinantes de desempeño.

The affirmative action policy "Argument of Inclusion" as a form of access to the public university: the case of Rio Grande do Norte Federal University

Before the approval of the Law $n$. 12.711/2012, which constitutionally institutes affirmative action in the access to federal universities in Brazil, different models of inclusion were discussed and applied in public institutions of Higher Education. This study analyzes and discusses the Argument of Inclusion (AI) - the affirmative action policy that provides additional scoring for applicants from public schools - that took place in the Rio Grande do Norte Federal University (UFRN) between the years of 2006-12. From an extensive database, the Ordinary Least Squares (OLS) technique was used as well as a Quantile Regression, considering as the variables of personal, socioeconomic and educational characteristics of the candidates from the Brazilian Vestibular exam 2010 of UFRN. The results show the relevance of the system of additional scoring as an incentive for inclusive access to universities, and points out new evidences around the variables that affect positively and negatively such access.

KEYWORDs: affirmative actions; access to university; Argument of Inclusion (AI); public policies; determinants of performance.

\section{Introdução}

No Brasil, a educação é um direito assegurado pela Constituição Federal. Desde a Constituição de 1934, o tema da educação possui um capítulo próprio, almejando assegurar esse direito à nossa sociedade. Enquanto o direito às três etapas da educação básica (infantil, fundamental e médio) é amplamente ofertado à população (Prado, 2008), ainda que enfrente percalços, o acesso ao ensino superior encara outra realidade.

A Constituição Federal de 1988, em seu art. 208, estabelece como dever do Estado "a garantia do acesso aos níveis mais elevados do ensino, da pesquisa e da criação artística, segundo a capacidade de cada um". Assim, o acesso às universidades públicas ocorre por meio 
de concursos (vestibulares ou, mais recentemente, Enem), em que as vagas são ofertadas em número muito menor do que sua procura. Se 73\% do total de matrículas no Ensino Superior encontram-se na rede privada de ensino, no Ensino Médio verifica-se o inverso: 83\% das matrículas estão na rede pública (Inep, 2013).

É possível perceber, então, um paradoxo na educação brasileira: os alunos do Ensino Médio privado, mais bem preparados para as provas de vestibular, acessam com maior facilidade o Ensino Superior público, enquanto alunos do Ensino Médio público se veem forçados a procurar o Ensino Superior em faculdades privadas. Dessa forma, o sistema educacional brasileiro, que pode ser considerado um dos mais seletivos do mundo, reflete um aprofundamento das desigualdades no acesso às oportunidades educacionais (Ribeiro, 1983 apud Queiroz, 2003).

A percepção do acesso reduzido de alunos do Ensino Médio público e de certos grupos étnicos à universidade pública levou à criação de políticas que visam à igualdade do acesso ao Ensino Superior. O sistema de reserva de vagas passou a ser amplamente discutido nas universidades públicas brasileiras durante os anos 2000, com diferentes fórmulas e níveis de adesão. Em 2009, dos 1.511.388 estudantes que entraram em universidades públicas, apenas 2,4\% entraram por meio de programas de reservas de vagas (Inep, 2009). Entre os tipos de programa (étnico, procedente de ensino público, social/renda familiar, pessoa com deficiência e outros), 69\% destinaram-se a alunos "procedentes de ensino público", seguido do relacionado com identidade "étnica", com 25\%.

Em 2012, O governo federal sancionou a Lei no 12.711/2012, que prevê a implementação gradual da reserva de $50 \%$ das matrículas nas universidades federais a alunos oriundos do Ensino Médio público. Enquanto esse programa ainda se encontra em processo de implementação, e que certamente poderá se revelar uma interessante fonte de dados futuros, o presente artigo busca extrair lições a partir de um dos projetos pilotos de reserva de vaga, desenhado e implementado no âmbito da Universidade Federal do Rio Grande do Norte (UFRN).

A política do Argumento de Inclusão (AI) - política de ação afirmativa que fornece pontuação adicional aos alunos provenientes de escolas públicas — foi instituída pela UFRN em 2006. Tal política demorou a ser difundida, e a vantagem oferecida, em forma de pontuação adicional, não foi significativa para permitir muitas aprovações nos seus primeiros anos. É apenas em 2010 (ano que será utilizado como referência para este estudo) que se observa um número considerável de candidatos ingressos a partir deste benefício.

A pesquisa aqui exposta pretende discutir a política de reserva de vagas no Ensino Superior público por meio de uma análise dos determinantes de acesso a essa modalidade de ensino - características pessoais, familiares e do meio. Para tanto, deter-se-á ao caso da Universidade Federal do Rio Grande do Norte (UFRN) e à sua política de ação afirmativa Argumento de Inclusão.

Para atingir o objetivo proposto, realizou-se uma pesquisa de cunho quantitativa, que se utilizou de dados do vestibular de 2010 da UFRN — ano da efervescência da política do AI na Universidade - para analisar o desempenho dos estudantes beneficiários e não beneficiários dessa ação afirmativa no exame. A base de dados cruzou informações referentes às caracte- 
rísticas familiares, socioeconômicas e de origem dos candidatos com suas notas nas diversas provas do vestibular no ano em questão. Essa análise se deu em algumas etapas, em que foram elaboradas as estatísticas descritivas, algumas regressões com a técnica dos Mínimos Quadrados Ordinários e, por fim, foi desenvolvida uma Regressão Quantílica para garantir a robustez dos resultados.

Muitos estudos acadêmicos discutem a relevância da aplicação de políticas de ação afirmativa para viabilizar o acesso das minorias às instituições públicas de ensino superior. Esses trabalhos fornecem contribuições interessantes para a discussão; no entanto, detêm-se usualmente no âmbito das opiniões e não na observação de dados concretos. A partir disso, este estudo se diferencia mediante a análise objetiva dos impactos do Argumento de Inclusão, uma política única, adotada entre os anos de 2006 e 2012 na UFRN para facilitar o acesso de alunos da rede pública de ensino ao nível universitário.

Nas próximas seções serão abordados alguns tópicos essenciais para situar e contextualizar a pesquisa, a partir de uma revisão da literatura sobre o tema.

\section{Aspectos determinantes para 0 acesso à universidade}

Diversos trabalhos já se dedicaram a levantar os aspectos relevantes ao desempenho de estudantes nos diversos níveis escolares e ao acesso ao Ensino Superior (Queiroz, 2003; Sampaio e Guimarães, 2009; Guimarães e Arraes, 2008). Prior (1984) apud Queiroz (2003), em pesquisas desenvolvidas durante as décadas de 1960 e 1970, concluiu que os aspectos socioeconômicos e de origem familiar mostram-se de influência poderosa na determinação do sucesso acadêmico.

Um dos aspectos mais destacados, nos diversos trabalhos encontrados, foi a disparidade entre os resultados dos alunos oriundos de escolas públicas e de escolas privadas. Conforme colocam Guimarães e Arraes (2008:14), “os rendimentos dos candidatos no vestibular que estudaram em escolas particulares são superiores aos daqueles que estudaram em escolas públicas". Sampaio e Guimarães (2009) enfatizam que os alunos que frequentaram a escola pública têm sua pontuação reduzida para cada ano adicional inseridos no sistema público.

Bollinger (2003) aponta para os gastos com ensino básico como determinante fundamental de acesso à universidade. De acordo com o autor, na virada do século, nos EUA, os distritos escolares mais ricos gastavam cerca de 10 vezes mais em educação dos que os mais pobres, e os estudantes pobres e de minorias étnicas se concentravam desproporcionalmente nos distritos escolares de menor renda (Bollinger, 2003). Como resultado dos investimentos mais baixos, as escolas nos distritos mais carentes contratavam professores menos qualificados e isso interferiria diretamente no desempenho dos alunos em testes, independentemente de raça. Com notas mais baixas nos SATs ${ }^{1}$ — que nos EUA são um dos fortes componentes

${ }^{1}$ Scholastic Assesment Test, exame educacional padrão realizado nos EUA. 
para a admissão no Ensino Superior - , tornava-se dificultado o acesso ao nível superior por parte de minorias étnicas, predominantes em regiões carentes.

Ao se fazer menção às minorias, é importante que fique claro o conceito genericamente aceito pela Organização das Nações Unidas em referência a tal questão: minorias são "grupos distintos dentro da população do Estado, possuindo características étnicas, religiosas ou linguísticas estáveis, que diferem daquelas do resto da população; em princípio numericamente inferiores ao resto da população; em uma posição de não dominância; vítima de discriminação" (Maia, 2014). Ao tratarmos de minorias no Brasil, destaca-se que, em termos numéricos, as minorias são muitas vezes maioria e, de acordo com Almeida e Carneiro (2003), as elites locais demonstram dificuldade de reconhecer a existência de minorias.

Queiroz (2003) ressalta que os estudos sobre o caráter seletivo do Ensino Superior no Brasil têm focado a análise de determinantes socioeconômicos do processo, deixando de lado elementos de raça, etnia e gênero. Assim, tal autor aponta que, diante da análise do desempenho dos estudantes segundo a condição étnica e o status socioeconômico, revelou-se que ao gradiente de cor corresponde uma gradação no desempenho do estudante, evidenciando que o melhor desempenho cabe aos que se consideram brancos e aos de status mais elevado (Queiroz, 2003). A comparação dos segmentos étnicos no nível de baixo status mostrou que, mesmo em condições socioeconômicas similares, os negros estão sujeitos a maiores desvantagens. Os oriundos da escola privada, em todos os segmentos étnicos, apresentam melhor desempenho que os da escola pública, em ambos os momentos.

Outro aspecto mencionado como diferencial entre os estudantes foi a formação dos membros da família. Para Guimarães e Arraes (2008), há prevalência de efeitos positivos sobre rendimentos dos candidatos no concurso de vestibular, caso os pais detenham um curso superior. Queiroz (2003:16) complementa que "a escolaridade do pai tem efeito sobre o desempenho do estudante, mostrando que os estudantes cujos pais possuem escolaridade superior têm maiores médias que aqueles cujo pai não completou o antigo curso primário". Sampaio e Guimarães (2009) defendem que o nível escolar da mãe impacta positivamente os resultados dos candidatos. No entanto, Guimarães e Arraes (2008) fazem a ressalva de que a titulação do pai apresentou um impacto levemente superior ao da titulação da mãe na probabilidade de o candidato pertencer ao grupo de melhor desempenho no geral.

Estudando o acesso ao Ensino Superior em meio ao estratificado sistema de castas na Índia, Basant e Sen (2014:809) encontram evidências que sustentam o nível educacional dos pais como fator de extrema importância:

Os resultados empíricos mostram que as chances de participação no Ensino Superior aumentam significativamente com o nível educacional dos pais e é maior com pais possuindo diploma de graduação. E este efeito persiste mesmo controlando variáveis como gastos domésticos (um proxy para status econômico) e filiação sociorreligiosa (casta e religião, que formam a base para reserva ou discussão de reserva).

Gonçalves e colaboradores (2010), utilizando microdados da Prova Brasil, estimaram modelos de regressão hierárquicos e detectaram um sinal positivo no coeficiente indicativo de 
renda familiar, representado a partir da propriedade de bens básicos (rádio, televisão e geladeira), detectando, portanto, uma relação direta entre o nível socioeconômico e a nota média das provas: quanto menor o nível socioeconômico, menor essa nota.

Além das variáveis mencionadas, Sampaio e Guimarães (2009) ainda indicam que o fácil acesso à internet, aulas de laboratório e aulas de idiomas também influenciam positivamente nos resultados dos alunos nos testes em questão.

\section{As políticas de ação afirmativa no contexto internacional e nacional}

O termo "ação afirmativa" pode ser definido como um princípio que institui desigualdades para promover a igualdade, atribuindo a alguns um tratamento preferencial, esperando-se com isso o restabelecimento de uma igualdade de oportunidades comprometida pela generalização ou persistência de práticas racistas ou sexistas ou, ainda, pela acentuação das desigualdades socioeconômicas (Villenave, 2006).

A expressão tem origem nos Estados Unidos, local que ainda se constitui como importante referência no assunto. Na década de 1960, os norte-americanos viviam um momento de reivindicações democráticas internas, expressas principalmente com o movimento pelos direitos civis, cuja bandeira central era a extensão da igualdade de oportunidades a todos. À época, as leis segregacionistas vigentes no país começam a ser eliminadas e o movimento negro surge como uma das principais forças atuantes, apoiado por liberais e progressistas brancos, unidos em busca da defesa de direitos. É nesse contexto que se desenvolve a ideia de uma ação afirmativa, exigindo que o Estado, para além de garantir leis antissegregacionistas, assumisse, também, uma postura ativa para a melhoria das condições da população negra (Moehlecke, 2002).

Os Estados Unidos já completam mais de 50 anos de experiências, mas a ação afirmativa não ficou restrita a eles. Experiências semelhantes ocorreram em vários países da Europa Ocidental, na Índia, Malásia, Austrália, Canadá, Nigéria, África do Sul, Argentina, Cuba, entre outros. Na Europa, as primeiras orientações nessa direção foram elaboradas em 1976, utilizando-se frequentemente a expressão ação ou discriminação positiva (Moehlecke, 2002).

No Brasil, a primeira iniciativa orientada pelos princípios da ação afirmativa no Congresso Nacional data de 1983, quando o senador Abdias do Nascimento lança o Projeto de Lei no 1.332, que visava à adoção de medidas de ação compensatória com a intenção de promover a participação de brasileiros negros em todos os níveis do emprego (público e privado), além da reserva de bolsas de estudo do Estado para estudantes negros e de vagas para negros no Instituto Rio Branco (para efeitos dessa lei, eram consideradas negras as pessoas que se enquadravam como pretos ou pardos, conforme a classificação adotada pelo IBGE) (Peria, 2004).

Desde então, já foram propostos diversos projetos com esse fim, ativados, principalmente, pela III Conferência Mundial das Nações Unidas contra o Racismo, a Discriminação Racial, a Xenofobia e a Intolerância Correlata, ocorrida em Durbin em 2001. Após isso, o então deputado estadual José Amorim trouxe o Projeto de Lei no $2.490 / 2001$, que deu origem à Lei no 3.708 - que estabeleceu a cota mínima de 40\% para populações negras e pardas e 50\% para os candidatos provenientes de escolas públicas no preenchimento das vagas relativas aos 
cursos de graduação da Universidade Estadual do Rio de Janeiro (Uerj) e da Universidade Estadual do Norte Fluminense (Uenf) (Amaral e Ribeiro, 2009).

O periódico online G1 mostra que, em 2012, das 59 universidades federais do país, 36 ofereciam algum tipo de ação afirmativa de reserva de vagas no processo seletivo. Destas, 25 tinham algum tipo de cota racial para negros, pardos e/ou índios. Em 2012 foi sancionada a Lei no $12.711 / 2012$, que prevê a implementação gradual da reserva de $50 \%$ das matrículas nas universidades federais para alunos que cursaram integralmente o Ensino Médio em escolas públicas. A aprovação dessa lei retirou a autonomia até então concedida às universidades federais para decidirem se adotariam políticas de ação afirmativa e como funcionaria tal política internamente.

\section{A polêmica da adoção de ações afirmativas no Brasil}

Apesar de já ter sido adotada em diversos países, quando se fala em ações afirmativas no contexto brasileiro, o assunto se torna bastante polêmico e contraditório. Enquanto parte da literatura se posiciona a favor das cotas, alguns autores são avessos a essa ideia. Maggie e Fry (2006) advertem que essas políticas que têm sido implementadas atualmente podem gerar consequências que vão além das portas das universidades. As políticas de cotas raciais podem trazer uma mudança radical no estatuto jurídico republicano brasileiro, que, até então, ignora "raça" e pune o racismo como crime hediondo, inafiançável e imprescritível. Como reflexo, os cidadãos seriam divididos em duas "raças" com direitos distintos, tornando, assim, a sociedade dividida entre "brancos" e "negros".

Em contrapartida, Amaral e Ribeiro (2009) dizem que não se trata de recusar o princípio da igualdade de respeito, mas torná-lo eficaz; ou seja, trata-se de reconhecer que grupos heterogêneos devem ser tratados heterogeneamente. Acrescentam, ainda, que certas identidades coletivas necessitam de proteção diferenciada, a fim de se garantir a inclusão social de todos.

Maggie e Fry (2006) criticam políticas de reservas de vagas como um "remédio barato e arriscado", com repercussões de longo prazo potencialmente negativas. Os autores complementam indagando se aqueles que estão propondo e aplicando essa política de reserva de vagas para negros conseguem perceber o que isso significa em termos da construção ou reconstrução da noção de "raça" no Brasil, pois se os estudantes dizem que "raça" não existe e que pertencem à raça humana, com a implantação das cotas raciais, terão que abdicar desse pressuposto lógico para concordar com a política pública em questão.

De acordo com Rosa (2014), em 1950, estudos apontaram certa reserva por parte dos brasileiros em discutir o tema do racismo. Balizados pelo discurso da democracia racial produzido nos anos 1930, muitos brasileiros afirmavam que não havia racismo no Brasil e, por conta disso, não deveria constar na pauta dos problemas nacionais.

Somente após os resultados encontrados por Bastide e Fernandes (1955), o discurso da democracia racial teve suas primeiras fissuras, e o tema do racismo, ainda que de forma incipiente, começou a ocupar espaço cada vez maior nos debates acadêmico, social e político. (Rosa, 2014:242) 
Ao se falar em políticas de cotas para o ensino superior, enquanto alguns dizem que quem é contra as cotas apenas defende os seus privilégios, outros pontuam que elas podem tirar o direito dos candidatos que passariam por mérito, caso não houvesse tal política.

Alon e Tienda (2007:507) confrontam o argumento do mérito apontando que a "definição de meritocracia que prevalece em meio a uma sociedade costuma expressar os interesses de grupos dominantes". Dessa forma, o excesso de ênfase em testes como parâmetro para admissão no Ensino Superior reflete os interesses daqueles com maiores recursos para se preparar para esses testes e o conceito de "mérito" passa a se resumir ao resultado de uma prova (Alon e Tienda, 2007). De acordo com os autores, a "aparentemente inevitável tensão entre mérito e diversidade existe apenas quando mérito é definido limitadamente pelo resultado dos SAT" (Alon e Tienda, 2007:507).

Há ainda a alegação de que o acesso facilitado irá reduzir a qualidade de ensino e pesquisa das universidades federais, que receberiam alunos que entraram mostrando um menor desempenho no vestibular. Quanto a isso, Alon e Tienda (2007) afirmam que a aprovação através de análise curricular mais ampla, avaliando o desempenho das notas dos alunos ao longo do Ensino Médio, é um melhor preditivo de sucesso acadêmico do que nota em testes de acesso ao Ensino Superior (como vestibular ou Enem), sendo compatível com o ideal da diversidade.

Estudando os impactos das políticas de Ação Afirmativa nos EUA, Gurin e colaboradores (2002:361) apontam positivamente o impacto da interação informal entre diferentes etnias no Ensino Superior, concluindo que "experiências de diversidade tiveram um impacto no pensamento ativo e engajamento intelectual e na orientação e sentimentos que estudantes irão precisar para se tonar líderes em uma democracia diversa". Whitla e colaboradores (2003) corroboram tais resultados através da avaliação positiva que alunos de medicina de universidades norte-americanas tiveram de uma educação tornada mais diversa por políticas da ação afirmativa.

Ao se destrinchar a literatura, parece haver um consenso de que as cotas para alunos de escolas públicas seriam como uma modalidade de reserva de vagas mais próxima das concepções de justiça distributiva. No entanto, há de se convir que, tanto em escolas públicas como em escolas privadas, encontram-se pessoas com poder aquisitivo mais baixo, o que poderia distorcer essa política.

\section{A política de incentivo na UFRN: Argumento de Inclusão}

A discussão de políticas de reserva de vagas no Ensino Superior público atingiu vários estados do Brasil durante os anos 2000, incluindo a análise de formas alternativas para o ingresso nos cursos de graduação. A UFRN inseriu-se nesse debate procurando respostas no sentido da adoção de novos mecanismos de acesso ao ensino superior e de aperfeiçoamento das formas já adotadas. Assim, conforme documento que relata estudo desenvolvido para repensar as políticas de acesso à UFRN (Comperve, 2004:7), aponta-se que o grande desafio seria 
manter a defesa do ensino público e gratuito como princípio norteador fundamental do modelo de oferta de ensino em nível superior e, aliado a isso, superar as dificuldades dos processos seletivos, buscando medidas afirmativas na proporção em que se reconhece que, na atual conjuntura, não se vislumbra, a curto prazo, uma melhoria qualitativa na oferta de ensino Fundamental e Médio. Reafirma-se, portanto, o princípio político da universidade pública para todos, mas, também, coloca-se, na agenda do debate, a necessidade de se criarem mecanismos para permitir o acesso ao ensino superior a determinados segmentos historicamente excluídos em decorrência de sua condição social.

A instituição reconhece que qualquer modelo de seleção utilizado estará sempre selecionando os candidatos tidos como mais aptos ao nível superior, sendo inevitável a não existência do filtro, pelo fato de a demanda por ensino superior ser sempre bem maior do que a oferta. E também pelo fato de as desigualdades no acesso ao ensino superior estarem fortemente relacionadas com as desigualdades sociais geradas pela estrutura social vigente.

Considerando que o modelo de exame vestibular já faz, devidamente, a seleção dos "mais aptos", o necessário seria que as mudanças pensadas para o processo seletivo pudessem ampliar as chances de as camadas sociais menos favorecidas ascenderem ao ensino superior público, o que representaria, à comissão que pensava tais políticas (2004), um passo a mais rumo à democratização do sistema educacional público.

Diante desse estudo sinteticamente apresentado, foi sugerido e adotado pela UFRN, a partir do vestibular de 2006, o chamado Argumento de Inclusão (AI). Conforme informações obtidas no site da Comperve (Comissão Permanente do Vestibular), o AI consistia em "um sistema de pontuação adicional, diferenciado, que considera, como referência, critérios socioeconômicos e de desempenho dos candidatos da rede pública no processo seletivo (vestibular)". Ainda se complementa, na mesma fonte, que se constitui em uma ação transitória, que tem como intuito ampliar o acesso dos alunos da rede pública que se colocam "sempre em desvantagem em relação aos alunos da rede privada".

O cálculo do Argumento de Inclusão foi desenvolvido inicialmente com base nos dados da demanda e do desempenho dos candidatos da rede pública em anos anteriores do processo seletivo. Até o vestibular de 2009, os Argumentos de Inclusão eram definidos para grupos de cursos e acrescidos no cálculo do Argumento de Classificação de candidatos da rede pública. Para o processo seletivo de 2010, conforme apresentado no edital, o beneficiário teve vantagem de $10 \%$ sobre os demais vestibulandos.

Com o passar dos anos, houve algumas alterações nos requisitos para utilização do AI devido, inclusive, a discussões no âmbito judicial. Como a base adotada neste estudo refere-se ao Vestibular de 2010, enfatiza-se que, para se beneficiar do AI no ano em questão, os candidatos deveriam ter cursado, com aprovação, na modalidade regular, do $7^{\circ}$ ao $9^{\circ}$ ano do Ensino Fundamental e as três séries do Ensino Médio em escolas da rede pública, além de cumprir com o requisito de não obter zero em nenhuma das provas objetivas.

A tabela 1 mostra a progressão do número de ingressos, semestre a semestre, através do Argumento de Inclusão, em suas diferentes categorias, do ano de 2006 ao ano de 2010. 


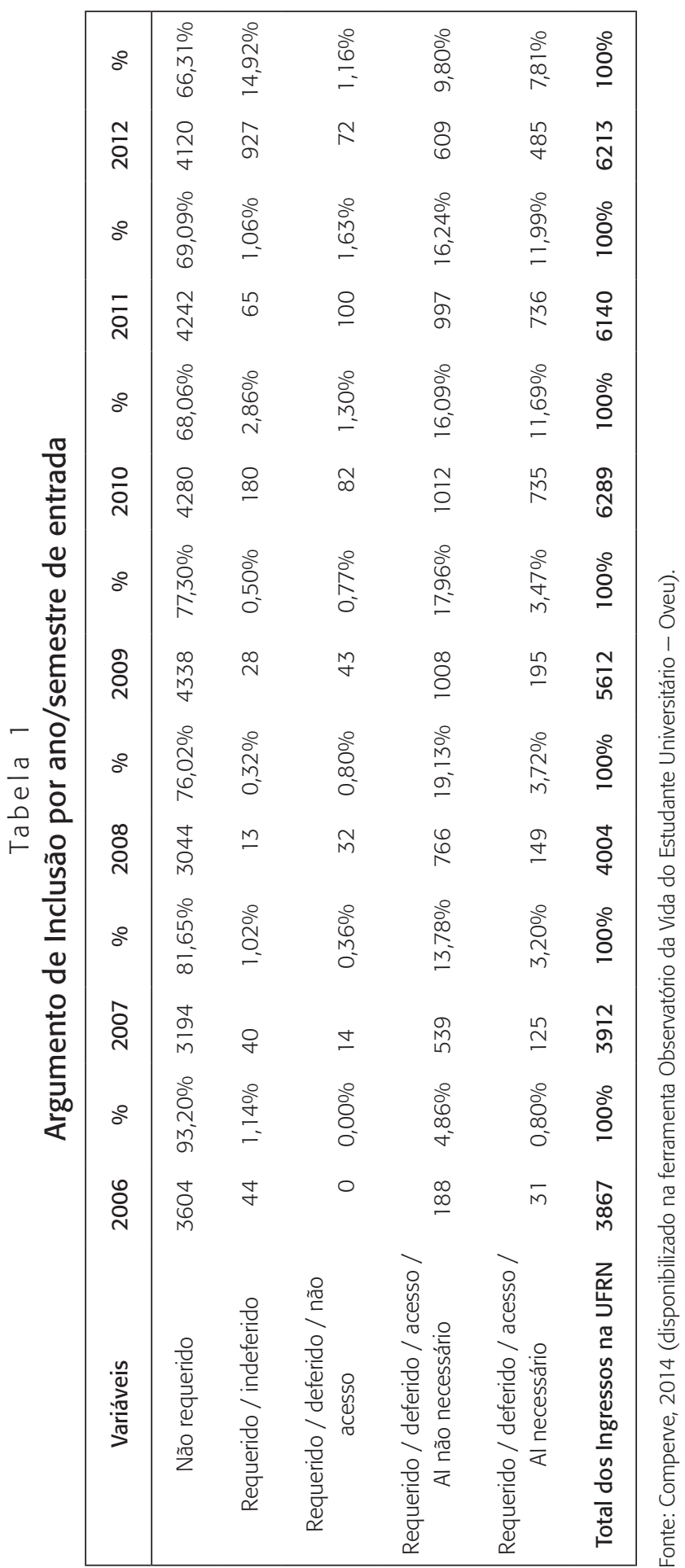


Conforme pode ser visto no quadro, o Argumento de Inclusão é apresentado em cinco categorias diferentes. A primeira se refere aos alunos que nem solicitaram o benefício, por não se enquadrarem em algum dos critérios exigidos, por não possuírem documentação comprobatória ou, até mesmo, por desconhecerem a política; a segunda categoria se refere aos candidatos que requisitaram o benefício, mas o tiveram negado; em seguida estão os candidatos que solicitaram o AI, tiveram o pedido deferido, mas não obtiveram pontuação suficiente (mesmo com o benefício) para entrar na universidade na primeira chamada; na quarta categoria estão os candidatos que pediram e receberam o benefício, entraram na universidade, mas o fariam mesmo sem a pontuação adicional; por fim, está a categoria dos candidatos que requisitaram e receberam o AI e só entraram na universidade devido a essa pontuação extra.

A tabela 1 mostra que no ano de 2006 apenas 31 candidatos só entraram na universidade devido à política do AI; já no ano de 2010 esse número foi para 735. Além da popularização da política, as mudanças anteriormente apresentadas também corroboraram para essa considerável mudança.

Como o foco do estudo está no ano de 2010, a seguir é apresentada uma tabela com todos os candidatos ao vestibular desse ano, subdivididos conforme a situação do AI.

Tabela 2

Argumento de Inclusão para os candidatos do vestibular $2010^{2}$

\begin{tabular}{ccc|}
\hline Variáveis & Candidatos 2010 & $\%$ \\
Não requerido & 16.112 & $64,57 \%$ \\
Requerido / indeferido & 1.111 & $4,45 \%$ \\
Requerido / deferido / não acesso & 5.912 & $23,69 \%$ \\
Requerido / deferido / acesso / Al não necessário & 1.052 & $4,22 \%$ \\
Requerido / deferido / acesso / Al necessário & 764 & $3,06 \%$ \\
Total de inscritos no vestibular 2010 da UFRN & 24.951 & $100 \%$ \\
\hline
\end{tabular}

Fonte: Comperve (2012).

\section{Metodologia}

A pesquisa teve o intuito de observar, explicar e discutir a política do Argumento de Inclusão e fatores decisivos ao desempenho no exame vestibular, a partir da análise das característi-

\footnotetext{
${ }^{2}$ As duas últimas categorias deveriam possuir os mesmos números para as duas tabelas (1 e 2). Isto não acontece devido ao fato de o primeiro quadro ter sido extraído do Oveu no site da Comperve, onde as tabulações foram feitas com base na primeira chamada. A segunda tabela , por sua vez, foi elaborada com a base de dados final, que considera os candidatos já após todas as chamadas do processo seletivo.
} 
cas pessoais, familiares e do meio. Buscou, ainda, comparar os desempenhos dos alunos que recebem o benefício do Argumento de Inclusão e dos demais alunos no exame vestibular. A pesquisa considera-se do tipo descritiva e explicativa, visto que teve como função principal a análise do objeto, descrevendo sua situação atual e identificando os fatores que determinam ou contribuem para a ocorrência dos fenômenos.

Quanto à sua abordagem, o estudo em questão é classificado como quantitativo e seu universo corresponde ao total de candidatos para o vestibular 2010 da UFRN. Para o ano determinado, podem-se observar um total de 27.054 inscrições, sendo, destas, 24.950 tidas como válidas - ao se excluir os que por algum motivo não obtiveram nota na primeira fase do exame - ; a amostra utilizada nas análises estatísticas cobre mais de $90 \%$ de todos os inscritos ao vestibular no ano em estudo. Apesar da opção por se analisar os dados do vestibular de 2010, o estudo foi desenvolvido predominantemente durante o período de 2010 a 2012.

Os dados foram disponibilizados pelo departamento de estatística da Comperve, órgão da UFRN responsável pela organização e aplicação do exame. Foram fornecidos dados referentes ao questionário socioeconômico coletado no período em que os estudantes estavam prestando vestibular e as notas parciais e finais de entrada dos candidatos à universidade. Esta ampla base de dados dá suporte aos objetivos do estudo, além de ser equivalente às bases utilizadas em pesquisas similares desenvolvidas em outras universidades do país.

Esta pesquisa teve algumas etapas de análise para atender aos objetivos propostos. Em um primeiro momento, trabalhou-se a base de dados, transformando as perguntas de natureza qualitativa (escala nominal) em variáveis binárias, que passam a assumir os valores 0 ou 1 , onde 1 significa a presença de um atributo e 0, sua ausência. Em seguida, foram elaboradas as estatísticas descritivas com um enfoque diferenciado para alunos que tiveram direito ao benefício do Argumento de Inclusão e para aqueles que não gozaram desse benefício. Essa análise permitiu traçar um perfil mais acurado dos alunos que prestam o exame vestibular da UFRN e ainda observar se existia alguma inconsistência na base.

Em seguida, foi utilizada a regressão por meio da técnica dos Mínimos Quadrados Ordinários (MQO), para observar os principais determinantes de acesso à universidade. Para essa regressão, adotou-se como a variável dependente — os escores das provas objetivas do vestibular (ARFASE1i) - Yi; e Xi, uma matriz de variáveis explicativas, incluindo características pessoais, antecedentes familiares, escola em que cursou o ensino fundamental e médio, entre outros. Foi utilizado o Argumento das provas objetivas devido ao fato de todos os candidatos fazerem as mesmas oito provas. Portanto, a seguinte regressão é aplicada:

$$
\text { ARFASE } 1 i=\beta_{0}+\beta_{1}^{*} \text { Ali }+\beta_{2} X i+\varepsilon i
$$

Onde $\beta_{0}$ representa a constante do modelo, AIi é uma variável binária que adota valor 1 para os candidatos que têm direito ao benefício do Argumento de Inclusão e 0 aos que não recebem tal auxílio, $\beta_{1}$ é o parâmetro de interesse, $\beta_{2}$ o vetor de parâmetros associados às variáveis explicativas (Xi) e $\varepsilon$ corresponde ao erro — as características não observadas. 
Em seguida, desenvolveu-se uma Regressão Quantílica, onde a base é dividida por quantis - de modo que os que tiveram menores notas (argfase1i) encontram-se no 1ํo quantil e os que obtiveram maiores notas estão situados no último quantil. Essa técnica nos permite uma análise mais apurada devido, inclusive, à robustez do modelo quanto à presença de outliers.

\section{Estatísticas descritivas}

A tabela 3 apresenta as estatísticas descritivas das variáveis utilizadas. Nas duas primeiras colunas são apresentados as médias e desvios de todos os candidatos, na terceira e quarta colunas os dados referentes aos candidatos que não recebem o benefício do Argumento de Inclusão e nas duas últimas os mesmos dados para os candidatos que recebem o benefício do AI.

Tabela 3

Estatísticas descritivas: média e desvio-padrão amostrais

\begin{tabular}{|c|c|c|c|c|c|c|}
\hline \multirow[b]{3}{*}{ Variáveis } & \multirow{2}{*}{\multicolumn{2}{|c|}{$\begin{array}{c}\text { Vestibular de } 2010 \\
(\mathrm{~N}=24.950)\end{array}$}} & \multirow{2}{*}{\multicolumn{2}{|c|}{$\begin{array}{c}\text { Candidatos sem Al } \\
(\mathrm{N}=17.221)\end{array}$}} & \multirow{2}{*}{\multicolumn{2}{|c|}{$\begin{array}{c}\text { Candidatos com Al } \\
(\mathrm{N}=7.729)\end{array}$}} \\
\hline & & & & & & \\
\hline & Mean & Std. Dev. & Mean & Std. Dev. & Mean & Std. Dev. \\
\hline Argumento da Fase 1 & 498,51 & 77,80 & 515,97 & 78,63 & 459,62 & 59,75 \\
\hline Mulher & 0,56 & 0,50 & 0,53 & 0,50 & 0,63 & 0,48 \\
\hline Idade & 20,72 & 5,78 & 20,66 & 5,96 & 20,86 & 5,37 \\
\hline Casado & 0,06 & 0,23 & 0,06 & 0,23 & 0,06 & 0,23 \\
\hline Mora com Pais & 0,82 & 0,38 & 0,83 & 0,38 & 0,81 & 0,40 \\
\hline Negro & 0,08 & 0,28 & 0,08 & 0,26 & 0,10 & 0,30 \\
\hline Pardo & 0,36 & 0,48 & 0,34 & 0,47 & 0,41 & 0,49 \\
\hline Outras Etnias & 0,02 & 0,15 & 0,02 & 0,15 & 0,02 & 0,16 \\
\hline Branco & 0,53 & 0,50 & 0,56 & 0,50 & 0,46 & 0,50 \\
\hline Católico & 0,66 & 0,47 & 0,65 & 0,48 & 0,68 & 0,47 \\
\hline Protestante & 0,17 & 0,38 & 0,16 & 0,37 & 0,20 & 0,40 \\
\hline Sem Religião & 0,11 & 0,31 & 0,12 & 0,32 & 0,08 & 0,27 \\
\hline Outra Religião & 0,04 & 0,19 & 0,04 & 0,20 & 0,03 & 0,18 \\
\hline Cursinho & 0,50 & 0,50 & 0,53 & 0,50 & 0,42 & 0,49 \\
\hline Renda Fam. até 1 SM & 0,18 & 0,38 & 0,08 & 0,27 & 0,39 & 0,49 \\
\hline Renda Fam. de 1 a 5 SM & 0,54 & 0,50 & 0,53 & 0,50 & 0,58 & 0,49 \\
\hline Renda Fam. de 5 a 10 SM & 0,18 & 0,38 & 0,25 & 0,43 & 0,02 & 0,15 \\
\hline Renda Fam. de 10 a 20 SM & 0,08 & 0,26 & 0,11 & 0,31 & 0,00 & 0,05 \\
\hline Renda Fam. mais de 20 SM & 0,03 & 0,16 & 0,04 & 0,20 & 0,00 & 0,02 \\
\hline Educ. da Mãe: Analfabeta & 0,04 & 0,19 & 0,02 & 0,14 & 0,08 & 0,26 \\
\hline Educ. da Mãe: Fundamental & 0,29 & 0,45 & 0,19 & 0,40 & 0,50 & 0,50 \\
\hline Educ. da Mãe: Ensino Médio & 0,38 & 0,48 & 0,40 & 0,49 & 0,33 & 0,47 \\
\hline Educ. da Mãe: Superior & 0,28 & 0,45 & 0,37 & 0,48 & 0,08 & 0,27 \\
\hline
\end{tabular}




\begin{tabular}{|lcccccc|}
\hline & \multicolumn{2}{c}{ Vestibular de 2010 } & \multicolumn{2}{c}{ Candidatos sem Al } & \multicolumn{2}{c|}{ Candidatos com Al } \\
\cline { 2 - 7 } \multicolumn{1}{c}{ Variáveis } & \multicolumn{2}{c}{$(\mathbf{N}=\mathbf{2 4 . 9 5 0})$} & \multicolumn{2}{c|}{$(\mathrm{N}=17.221)$} & \multicolumn{2}{c|}{$(\mathrm{N}=7.729)$} \\
\cline { 2 - 7 } & Mean & Std. Dev. & Mean & Std. Dev. & Mean & Std. Dev. \\
\hline Ens. Médio: Escola Pública & 0,48 & 0,50 & 0,25 & 0,43 & 1,00 & 0,00 \\
Ens. Médio: Escola Privada & 0,45 & 0,50 & 0,65 & 0,48 & 0,00 & 0,00 \\
Internet em Casa & 0,57 & 0,50 & 0,70 & 0,46 & 0,27 & 0,44 \\
Hábito de Leitura & 0,59 & 0,49 & 0,60 & 0,49 & 0,58 & 0,49 \\
Estudante & 0,75 & 0,43 & 0,76 & 0,43 & 0,73 & 0,45 \\
Trabalha & 0,24 & 0,43 & 0,22 & 0,42 & 0,27 & 0,44 \\
Supletivo & 0,05 & 0,21 & 0,07 & 0,25 & 0,00 & 0,04 \\
Enem: Acima Média & 0,14 & 0,35 & 0,15 & 0,35 & 0,14 & 0,35 \\
Enem: Na Média & 0,16 & 0,37 & 0,13 & 0,33 & 0,25 & 0,43 \\
Enem: Abaixo da Média & 0,07 & 0,25 & 0,04 & 0,19 & 0,14 & 0,35 \\
Não fez Enem & 0,62 & 0,48 & 0,69 & 0,46 & 0,47 & 0,50 \\
\hline
\end{tabular}

Nota: No caso dos candidatos sem Al, os Argumentos da fase 1 mínimo e máximo equivalem a 166,62 e 768,73, respectivamente. Já no que se refere aos candidatos com Al, essas notas são 144,27 e 706,05.

Fonte: Dados da pesquisa, 2012.

A amostra é constituída por estudantes que têm de 20 a 21 anos de idade em média, variando de 14 a 69 anos de idade. 56\% da amostra é composta por mulheres; no entanto, entre os que recebem o AI, esse percentual eleva-se para 63\%. Aproximadamente $94 \%$ são solteiros, a maioria (82\%) ainda mora com os pais e $75 \%$ dos candidatos têm o estudo como principal atividade (são estudantes). Entre os candidatos que não recebem o AI, 76\% são estudantes, já dos candidatos que recebem o AI, 73\% são estudantes. Quanto à "raça", a maioria dos alunos classifica-se como branco ou pardo.

Grande parte dos inscritos tem renda familiar mensal entre 1 e 5 salários mínimos. No entanto, pode-se perceber que entre os beneficiários praticamente não existem candidatos com renda familiar acima de 5 salários mínimos. Já entre os candidatos que não recebem o benefício do $\mathrm{AI}$ encontram-se 63\% com renda até 5 salários mínimos.

Em torno de 38\% das mães dos candidatos têm grau de escolaridade até o Ensino Médio; e dos candidatos que não recebem o benefício do AI, 37\% têm mãe com nível superior, enquanto, entre os beneficiários, estas correspondem a apenas $8 \%$.

Quando se trata do sistema de ensino, a distribuição entre alunos provenientes de escolas públicas e privadas é praticamente equivalente, onde $48 \%$ vêm de escolas públicas. Entre os candidatos que recebem o AI, todos cursaram o Ensino Médio em escola pública, visto que esse é um dos requisitos essenciais para obter tal auxílio; já entre os que não recebem o AI, 25\% cursaram o Ensino Médio exclusivamente em escola pública. 
No que se refere aos hábitos de leitura, 59\% colocam ter lido mais de dois livros no ano em que prestaram o exame, excetuando-se os livros escolares e as obras exigidas para o exame.

Além da modalidade regular de ensino, no Brasil é oferecido, em algumas escolas, um método alternativo de educação para alunos que estão fora da faixa etária. Esse método alternativo é chamado Supletivo ou EJA (Ensino de Jovens e Adultos) e permite que estes alunos acelerem a conclusão do ensino, estudando uma série por semestre. Nas bases de dado utilizadas neste estudo, cerca de $5 \%$ da amostra concluiu os estudos nessa modalidade de curso.

Ressalta-se ainda que, ao se avaliar a diferença entre as médias das notas dos candidatos que recebem o $\mathrm{AI}(459,62)$ e daqueles que não recebem $(515,96)$, observa-se uma discrepância média de 56,35 pontos. No momento em que o benefício do AI corresponde a um fator multiplicador de 1,1, ou seja, 10\% extra na nota final, pode-se fazer a seguinte constatação:

$$
459,62 * 1,1=505,58<515,96
$$

Ou seja, a média da primeira fase, dos candidatos que têm direito ao AI, acrescida de $10 \%$, ainda é inferior à média da nota dos candidatos que não têm direito ao benefício do AI. Essa observação é bastante primária. Além disso, utiliza-se do Argumento da Fase 1 como referência, enquanto o AI incide sobre o Argumento Final, que inclui as provas discursivas.

\section{Resultados da regressão MQO}

A tabela 4 mostra os resultados obtidos a partir da Regressão dos Mínimos Quadrados Ordinários (MQO). Para permitir uma melhor visualização, foram estimadas cinco regressões. Tendo sempre o Argumento da primeira fase (argfase1) como variável dependente, na primeira regressão foi incluído apenas o Argumento de Inclusão e os demais controles que não estão diretamente ligados e não definem a política do AI no ano de 2010; na segunda, foi incluída a variável Renda Familiar; já na terceira regressão, além das variáveis explicativas anteriores, foram incluídas uma variável dummy para quem fez cursinho e outra para quem cursou o ensino Médio/Técnico no IFRN. Esta última variável binária entra como um controle extremamente relevante na regressão, pois o IFRN é uma escola pública federal muito conceituada por fornecer ensino de qualidade e possui, ainda, um exame bastante severo para ingresso, o que garante que os alunos oriundos dessa escola já pertencem a uma elite intelectual préselecionada; a quarta regressão incluiu uma variável para Tipo de Ensino Médio - escola particular (usada como referência), escola pública ou outro tipo de escola (parte em escola pública e parte em particular ou outros); e, por fim, na quinta regressão, são mantidos todos os controles anteriores, mas é retirada a variável do Argumento de Inclusão para que se possa observar melhor o contraste entre o ensino público e ensino privado, conforme feito em outras pesquisas correlatas. 
Tabela 4

Al e variáveis de desempenho no vestibular UFRN: estimações por MQO

\begin{tabular}{|c|c|c|c|c|c|}
\hline \multicolumn{6}{|c|}{ Variável dependente: argfase 1} \\
\hline & $1 \underline{a}$ & $2^{\mathrm{a}}$ & 3a & $4^{\mathrm{a}}$ & 5 a \\
\hline \multirow[t]{2}{*}{ Argumento de Inclusão } & $-24,438$ & $-17,362$ & $-18,573$ & $-2,547$ & Não \\
\hline & $(24,47)^{* *}$ & $(17,28)^{* *}$ & $(18,88)^{* *}$ & $(2,20)^{*}$ & \\
\hline \multirow[t]{2}{*}{ Ensino Médio: Público } & Não & Não & Não & $-33,912$ & $-35,324$ \\
\hline & & & & $(27,72)^{* *}$ & $(33,92)^{* *}$ \\
\hline \multirow[t]{2}{*}{ Ensino Médio: Outro } & Não & Não & Não & $-19,341$ & $-19,357$ \\
\hline & & & & $(12,63)^{* *}$ & $(12,64)^{* *}$ \\
\hline \multirow[t]{2}{*}{ IFRN } & Não & Não & 66,878 & 83,422 & 83,922 \\
\hline & & & $(31,40)^{* *}$ & $(38,21)^{* *}$ & $(38,65)^{* *}$ \\
\hline \multirow[t]{2}{*}{ Cursinho } & Não & Não & 11,749 & 12,012 & 12,070 \\
\hline & & & $(15,04)^{* *}$ & $(15,62)^{* *}$ & $(15,71)^{* *}$ \\
\hline \multirow[t]{2}{*}{ Renda da Família 1} & Não & $-16,149$ & $-13,881$ & $-11,445$ & $-11,722$ \\
\hline & & $(14,11)^{* *}$ & $(12,39)^{* *}$ & $(10,34)^{* *}$ & $(10,66)^{* *}$ \\
\hline \multirow[t]{2}{*}{ Renda da Família 3} & Não & 22,951 & 22,379 & 17,744 & 17,843 \\
\hline & & $(20,49)^{* *}$ & $(20,45)^{* *}$ & $(16,28)^{* *}$ & $(16,38)^{* *}$ \\
\hline \multirow[t]{2}{*}{ Renda da Família 4} & Não & 39,066 & 39,205 & 33,319 & 33,366 \\
\hline & & $(24,51)^{* *}$ & $(25,16)^{* *}$ & $(21,51)^{* *}$ & $(21,54)^{* *}$ \\
\hline \multirow[t]{2}{*}{ Renda da Família 5} & Não & 51,000 & 50,846 & 45,063 & 45,103 \\
\hline & & $(21,01)^{* *}$ & $(21,42)^{* *}$ & $(19,21)^{* *}$ & $(19,22)^{* *}$ \\
\hline \multirow[t]{2}{*}{ Mulher } & $-18,711$ & $-16,871$ & $-17,297$ & $-18,086$ & $-18,151$ \\
\hline & $(22,41)^{* *}$ & $(20,66)^{* *}$ & $(21,65)^{* *}$ & $(22,97)^{* *}$ & $(23,07)^{* *}$ \\
\hline \multirow[t]{2}{*}{ Idade até 18 anos } & 5,812 & 6,017 & 11,207 & 10,880 & 10,817 \\
\hline & $(4,84)^{* *}$ & $(5,13)^{* *}$ & $(9,70)^{* *}$ & $(9,57)^{* *}$ & $(9,52)^{* *}$ \\
\hline \multirow[t]{2}{*}{ Idade maior que 18 anos } & $-9,377$ & $-8,712$ & $-9,350$ & $-7,218$ & $-7,166$ \\
\hline & $(8,40)^{* *}$ & $(7,99)^{* *}$ & $(8,78)^{* *}$ & $(6,87)^{* *}$ & $(6,82)^{* *}$ \\
\hline \multirow[t]{2}{*}{ Negro } & $-6,377$ & $-4,450$ & $-4,264$ & $-3,819$ & $-3,797$ \\
\hline & $(4,41)^{* *}$ & $(3,15)^{* *}$ & $(3,09)^{* *}$ & $(2,81)^{* *}$ & $(2,79)^{* *}$ \\
\hline \multirow[t]{2}{*}{ Pardo } & $-0,836$ & 0,158 & $-0,155$ & $-0,159$ & $-0,194$ \\
\hline & $(1,00)$ & $(0,19)$ & $(0,19)$ & $(0,20)$ & $(0,25)$ \\
\hline \multirow[t]{2}{*}{ Outras Etnias } & $-9,253$ & $-8,387$ & $-8,081$ & $-7,602$ & $-7,592$ \\
\hline & $(3,64)^{* *}$ & $(3,38)^{* *}$ & $(3,33)^{* *}$ & $(3,18)^{* *}$ & $(3,18)^{* *}$ \\
\hline \multirow[t]{2}{*}{ Educ. Mãe: Analfabeta } & $-12,672$ & $-8,847$ & $-6,643$ & $-4,394$ & $-4,544$ \\
\hline & $(5,85)^{* *}$ & $(4,16)^{* *}$ & $(3,19)^{* *}$ & $(2,14)^{*}$ & $(2,22)^{*}$ \\
\hline \multirow[t]{2}{*}{ Educ. Mãe: Fundamental } & $-8,694$ & $-6,254$ & $-5,346$ & $-2,891$ & $-3,021$ \\
\hline & $(8,67)^{* *}$ & $(6,34)^{* *}$ & $(5,54)^{* *}$ & $(3,03)^{* *}$ & $(3,17)^{* *}$ \\
\hline Educ. da Mãe: Superior & 18,808 & 10,566 & 10,878 & 9,055 & 9,078 \\
\hline
\end{tabular}




\begin{tabular}{|c|c|c|c|c|c|}
\hline \multicolumn{6}{|c|}{ Variável dependente: argfase 1} \\
\hline & $1^{\underline{a}}$ & $2^{\mathrm{a}}$ & 3a & $4^{\mathrm{a}}$ & $5^{\text {a }}$ \\
\hline \multirow{3}{*}{ Internet em Casa } & $(18,90)^{* *}$ & $(10,55)^{* *}$ & $(11,12)^{* *}$ & $(9,38)^{* *}$ & $(9,41)^{* *}$ \\
\hline & 14,829 & 6,380 & 5,780 & 3,028 & 3,182 \\
\hline & $(16,56)^{* *}$ & $(6,99)^{* *}$ & $(6,48)^{* *}$ & $(3,43)^{* *}$ & $(3,61)^{* *}$ \\
\hline \multirow[t]{2}{*}{ Hábito de Leitura } & 10,538 & 10,764 & 10,006 & 10,075 & 10,076 \\
\hline & $(13,18)^{* *}$ & $(13,79)^{* *}$ & $(13,12)^{* *}$ & $(13,41)^{* *}$ & $(13,41)^{* *}$ \\
\hline \multirow[t]{2}{*}{ Supletivo } & $-25,355$ & $-22,637$ & $-20,577$ & $-17,233$ & $-16,674$ \\
\hline & $(13,15)^{* *}$ & $(12,02)^{* *}$ & $(11,18)^{* *}$ & $(9,44)^{* *}$ & $(9,23)^{* *}$ \\
\hline Outros Controles ${ }^{3}$ & Sim & Sim & Sim & Sim & Sim \\
\hline \multirow[t]{2}{*}{ Constante } & 465,177 & 466,346 & 461,818 & 480,275 & 480,356 \\
\hline & $(136,08)^{* *}$ & $(138,87)^{* *}$ & $(140,32)^{* *}$ & $(145,15)^{* *}$ & $(145,17)^{* *}$ \\
\hline $\mathrm{R}^{2}$ & 0,39 & 0,42 & 0,45 & 0,46 & 0,46 \\
\hline N & 24.950 & 24.950 & 24.950 & 24.950 & 24.950 \\
\hline
\end{tabular}

Nota: * indica significância em nível de confiança de 95\% ( $<<0,05)$ e ** significância em nível de confiança de 99\% $(p<0,01)$. Estas regressões podem ser visualizadas na íntegra no Apêndice A deste trabalho.

Fonte: Dados da pesquisa, 2012.

Conforme pode ser observado, na primeira regressão os candidatos que recebem o AI têm um déficit de, em média, 24,47 pontos em relação àqueles que não têm o benefício; essa diferença, no entanto, é reduzida a $-2,55$ pontos, ao serem incluídas variáveis explicativas como Renda Familiar, Cursinho e Tipo de Ensino Médio na regressão. Isto mostra que no momento em que são incluídos todos os controles, o fato de o candidato receber ou não o benefício do AI não apresenta demasiado impacto. Esse era um resultado já esperado (e até mesmo buscado), pois a seleção dos candidatos que recebem o Argumento de Inclusão é baseada justamente no fato de os alunos terem estudado em escolas públicas. O resultado obtido, no entanto, apesar de pequeno, ainda se apresenta significante, o que pode ser explicado, provavelmente, devido à impossibilidade de se saber (e se controlar) exatamente quais anos do ensino fundamental foram feitos em escola pública e o benefício do AI ser concedido aos alunos que cursaram os três últimos anos do fundamental em escola pública.

Antes de se incluir o controle para tipo de escola, observa-se que o Argumento de Inclusão tem impacto de 18,57 pontos negativos, o que representa que a nota média dos candidatos que recebem o AI, ao ser controlada, é ainda inferior à média das notas dos candidatos que não ganham esse benefício.

\footnotetext{
${ }^{3}$ A Regressão também foi controlada para as seguintes informações dos candidatos: religião, se trabalha, só estudante, turno, já prestou vestibular, já ingressou na universidade, nota do Enem, áreas, estado civil, tamanho da família e se mora com os pais.
} 
A literatura, por sua vez, discute bastante as políticas afirmativas e sua configuração, pois surgem como solução imediata para atenuar desigualdades sociais, mas podem, em sua busca por justiça, trazer uma série de injustiças. De acordo com o apresentado no referencial teórico, a política do AI tem sido ajustada ano a ano; já se alterou a pontuação adicional concedida, que até o ano de 2009 era mais contida, e os critérios têm sido modificados de modo a captar cada vez mais alunos que tenham cursado mais anos no ensino público.

Conforme esperado, os resultados apresentados confirmam que os alunos que frequentam o ensino público tendem a ter resultados inferiores (-33,91 pontos) no vestibular que aqueles oriundos do ensino privado. Isso é um reflexo da qualidade do ensino nessas escolas, mesmo se parcialmente controlado por incluirmos a variável referente ao grau de escolaridade da mãe. Esse resultado pode ser observado em diversos outros artigos que abordam o tema, Guimarães e Arraes (2008) e Sampaio e Guimarães (2009), que pontuam que frequentar uma escola privada em vez de uma escola pública tem um grande efeito positivo sobre os resultados dos testes padronizados.

Embora o resultado dos candidatos da escola pública seja inferior, o Instituto Federal do Rio Grande do Norte (IFRN), que oferece ensino médio público e gratuito para alunos seletos, costuma obter elevada pontuação no vestibular. Observa-se que a nota dos alunos de escola técnica apresenta-se 83,42 pontos maior que a dos demais candidatos. Esse é um diferencial bastante representativo; no entanto, é essencial lembrar que os alunos que entram no IFRN já foram pré-selecionados, tendo em vista o número de vagas reduzidas e o exame que garante $50 \%$ das vagas para os melhores alunos de escolas públicas.

Outro aspecto observado refere-se aos cursinhos e cursos isolados. Alunos que frequentam esses cursos, que normalmente vêm em complemento às aulas regulares, tendem a ter notas quase 12,01 pontos superior em relação à nota de outros alunos que não frequentaram cursinhos.

Assim como pode ser visto em outros estudos, a renda familiar mostra-se influente no desempenho do candidato no exame. Quanto maior a renda da família, maior a nota. Para esta regressão, utilizou-se como referência a faixa de 1 a 5 salários mínimos, onde os candidatos que possuem renda familiar inferior obtêm, em média, uma nota 11,45 pontos inferior, enquanto candidatos em famílias com faixa de renda superior a 20 salários mínimos têm notas maiores, em média, 45,05 pontos. Observa-se que, quanto maior a faixa de renda da família, maior é a média de notas dos candidatos.

Quanto ao gênero dos candidatos, assim como constatado em trabalhos anteriores (Emilio, Alves e Beluzzo, 2004; Guimarães e Sampaio, 2007), os candidatos do sexo feminino obtêm, em média, 18,09 pontos a menos que os candidatos do sexo masculino. A partir desse resultado, considerando o fato de existirem mais candidatos do sexo feminino prestando o exame, pode-se sugerir que vários homens que realmente não têm bom desempenho escolar nem se candidatem ao vestibular.

No que se refere à idade do candidato, utilizou-se como referência 18 anos, visto que a maioria dos estudantes no Brasil que presta vestibular o faz com essa idade, assim que conclui o Ensino Médio. Assim como no estudo de Guimarães e Sampaio (2007), observou-se que, de 
modo geral, a idade influencia negativamente o resultado do vestibular. A maioria dos estudantes com mais de 18 anos que prestam o exame vestibular está normalmente desnivelada — o que pode derivar de uma reprovação; ou já concluiu o Ensino Médio há algum tempo e, como a prova é elaborada com base nos conhecimentos escolares, um distanciamento desse ambiente representa uma desvantagem ao candidato.

No que tange às origens étnico-raciais do candidato, o grupo foi subdividido em quatro variáveis dicotômicas: candidatos que se consideram brancos (variável que serviu de base na regressão), pardos, negros (e remanescentes de quilombolas) e outras etnias (abrange candidatos de origem indígena ou oriental). Visto que muitas universidades no Brasil enveredaram as suas políticas de incentivo para ingresso para pessoas que se autodenominam indígenas, negras ou pardas, enquanto grupos de minorias socialmente desprivilegiadas, esta se torna uma questão polêmica e que deve ser cuidadosamente analisada. Nos resultados apresentados, nota-se que existe uma pequena disparidade, mas ainda assim significativa, entre os candidatos que se autodenominam negros e os brancos no valor médio de -3,82 pontos. Quanto aos candidatos pardos, o resultado não se mostrou significante; e os de outras etnias apresentaram um resultado significativamente negativo (-7,60 pontos).

A composição étnica do Rio Grande do Norte difere um pouco de outros estados brasileiros, pois é predominantemente composta por brancos e pardos, devido à colonização europeia. Os dados analisados apenas confirmam tal contexto, e mostra que a questão das diferenças étnicas tem uma representatividade bastante baixa na base estudada quando comparada a questões como renda familiar e escola de origem.

O estado civil dos candidatos não tem efeito significativo. No entanto, quanto ao tamanho da família, nota-se que candidatos de famílias menores (até quatro pessoas) tendem a ter notas maiores no vestibular ao serem comparados aos candidatos que vivem em casas com mais de quatro pessoas. Seguindo ainda esse raciocínio, os candidatos que moram com os pais têm resultados em média 6 pontos inferior.

No que se refere à religião, foram utilizados os candidatos da religião católica como parâmetro. Comparados a estes, os candidatos protestantes apresentaram nota 2,87 pontos superior e os de outras religiões, 7,47 pontos maior; os candidatos que se colocam sem religião, por sua vez, possuem em média nota 19,06 superior. Esse resultado é similar ao encontrado em Guimarães e Sampaio (2007), onde ateus, pessoas de religiões africanas, judeus, protestantes e candidatos que declararam ter outras crenças religiosas tiveram performances superiores à dos católicos em média $(3,7 ; 5,9 ; 5,1 ; 0,64$ e 2,4 pontos percentuais, respectivamente).

Conforme se observa na revisão bibliográfica (Queiroz, 2003; Emilio, Alves e Beluzzo, 2004; Guimarães e Sampaio, 2007; Guimarães e Arraes, 2008), outro aspecto que se destaca refere-se à escolaridade da mãe. Os resultados mostram que, quanto maior o grau de escolaridade da mãe do candidato, maior a nota deste no exame. Na regressão, foram utilizados como referência os candidatos cujas mães encerraram os seus estudos no Ensino Médio (completo ou incompleto); observa-se que os candidatos cujas mães possuem educação inferior a esse nível têm notas em média menores e aqueles cujas mães cursam ou cursaram o nível superior ou 
de pós-graduação têm notas maiores. Pode-se supor que, de um modo geral, pais com maior escolaridade tenham a possibilidade de dar um apoio ao estudante, além de permitir um ambiente mais propício para trocas e conversas sobre questões acadêmicas. Normalmente, se os pais têm maior escolaridade, é comum que o candidato tenha mais contato com a língua culta e formal, respeitada e considerada correta no ambiente acadêmico. Além disso, pode-se supor a existência de fatores genéticos como a inteligência e considerar características de adaptação ao ambiente escolar enquanto hereditárias.

$\mathrm{O}$ acesso à internet em casa também se mostrou significativo, de modo que, mesmo controlado para renda, estes candidatos têm notas 3,03 pontos maior. Os alunos que colocam ter hábitos de leitura - leram ao menos dois livros paradidáticos no ano do vestibular (além das obras exigidas na prova) — têm notas superiores (10,08 pontos). De modo geral, pessoas que costumam ler mais livros têm mais contato com a língua e com outros conhecimentos relevantes. Subentende-se, ainda, que os candidatos que leem mais livros têm mais facilidade para tal.

O fato de o candidato trabalhar, medido a partir da sua participação na renda familiar, não foi significativo na regressão; no entanto, aqueles que se colocaram como estudantes ou sem ocupação apresentaram notas médias superiores àqueles que designam-se a outras ocupações profissionais.

Em consonância ao apresentado nos resultados de Guimarães e Sampaio (2007), os alunos que concluíram o ensino médio supletivo apresentaram notas 17,23 pontos menor, em média. Apesar da representativa discrepância entre esses alunos e os que fazem o ensino regular e mesmo o ensino supletivo sendo, muitas vezes, público, estes não têm direito ao Argumento de Inclusão no ano estudado.

No que se refere ao número de vestibulares que o candidato já prestou, nota-se que os alunos que fazem mais vezes o exame costumam ter, em média, notas superiores aos demais. Esse resultado é válido também para aqueles alunos que já ingressaram anteriormente em um curso superior. O resultado da prova do Enem também se apresenta relevante, mostrando que há certa sintonia - notas acima da média no Enem refletem positivamente nos resultados obtidos no vestibular.

\section{Resultados da Regressão Quantílica}

Como complemento aos resultados ora apresentados na Regressão MQO, são apresentados a seguir os resultados da Regressão Quantílica, em que se mostra uma estratégia empírica apropriada ao ajustar o modelo através de diferentes pontos da distribuição amostral condicional.

Na Regressão Quantílica, a base é dividida por quantis - que, neste caso, corresponde à ordenação dos dados em sete subconjuntos de dimensão essencialmente igual — estabelecidos a partir de pontos de corte que determinam as fronteiras entre os subconjuntos consecutivos. Ou seja, os subconjuntos agrupam os candidatos por seus Argumentos Parciais, de modo que os que tiveram menores notas (argfase1) se encontram no $20^{\circ}$ quantil (Q 0,2 - referente 
aos $20 \%$ dos candidatos com notas inferiores) e os que obtiveram maiores notas estão situados do 80 quantil (Q 0,8 - representa os alunos com melhores notas).

Para tanto, são apresentadas estimativas de regressões quantílicas para os quantis 0,2 ; 0,$3 ; 0,4 ; 0,5 ; 0,6$; 0,7 e 0,8, na tabela 5 . Em seguida, apresentam-se, nas figuras 1 a 3 , os coeficientes da estimação quantílica para um contínuo de quantis diferentes para as variáveis: Argumento de Inclusão (c_ai); se cursou o ensino médio/técnico no Instituto Federal do RN (IFRN); e Renda Familiar (uma variável para cada faixa de renda).

Tabela 5

Al e variáveis de desempenho no vestibular UFRN: regressão por quantis para o ano de 2010

\begin{tabular}{|c|c|c|c|c|c|c|c|}
\hline \multicolumn{8}{|c|}{ Variável dependente: argfase 1} \\
\hline & Q 0,2 & Q 0,3 & Q 0,4 & Q 0,5 & Q 0,6 & Q 0,7 & Q 0,8 \\
\hline \multirow[t]{2}{*}{ Argumento de Inclusão } & $-11,60$ & $-13,809$ & $-15,077$ & $-17,342$ & $-19,079$ & $-21,467$ & $-23,312$ \\
\hline & $(8,93)^{* *}$ & $(12,16)^{* *}$ & $(14,55)^{* *}$ & $(15,44)^{* *}$ & $(17,73)^{* *}$ & $(17,93)^{* *}$ & $(18,85)^{* *}$ \\
\hline \multirow[t]{2}{*}{ IFRN } & 67,277 & 67,757 & 67,690 & 71,948 & 70,226 & 71,480 & 69,857 \\
\hline & $(25,06)^{* *}$ & $(28,32)^{* *}$ & $(30,60)^{* *}$ & $(29,58)^{* *}$ & $(29,69)^{* *}$ & $(26,73)^{* *}$ & $(24,73)^{* *}$ \\
\hline \multirow[t]{2}{*}{ Cursinho } & 10,300 & 10,540 & 10,858 & 10,765 & 11,621 & 12,797 & 12,640 \\
\hline & $(10,39)^{* *}$ & $(11,93)^{* *}$ & $(13,34)^{* *}$ & $(12,08)^{* *}$ & $(13,44)^{* *}$ & $(13,09)^{* *}$ & $(12,26)^{* *}$ \\
\hline \multirow[t]{2}{*}{ Renda da Família 1} & $-8,93$ & $-10,346$ & $-11,478$ & $-13,048$ & $-14,099$ & $-13,601$ & $-15,517$ \\
\hline & $(6,20)^{* *}$ & $(8,14)^{* *}$ & $(9,81)^{* *}$ & $(10,20)^{* *}$ & $(11,40)^{* *}$ & $(9,79)^{* *}$ & $(10,63)^{* *}$ \\
\hline \multirow[t]{2}{*}{ Renda da Família 3} & 19,03 & 19,798 & 22,182 & 25,099 & 25,673 & 25,399 & 27,639 \\
\hline & $(13,69)^{* *}$ & $(16,06)^{* *}$ & $(19,50)^{* *}$ & $(20,08)^{* *}$ & $(21,10)^{* *}$ & $(18,35)^{* *}$ & $(18,80)^{* *}$ \\
\hline \multirow[t]{2}{*}{ Renda da Família 4} & 33,57 & 37,651 & 40,835 & 44,035 & 43,012 & 44,294 & 44,898 \\
\hline & $(16,83)^{* *}$ & $(21,38)^{* *}$ & $(25,17)^{* *}$ & $(24,76)^{* *}$ & $(24,86)^{* *}$ & $(22,54)^{* *}$ & $(21,43)^{* *}$ \\
\hline \multirow[t]{2}{*}{ Renda da Família 5} & 51,13 & 51,399 & 52,588 & 54,302 & 55,037 & 56,893 & 58,038 \\
\hline & $(17,06)^{* *}$ & $(19,29)^{* *}$ & $(21,32)^{* *}$ & $(20,07)^{* *}$ & $(20,86)^{* *}$ & $(18,94)^{* *}$ & $(18,22)^{* *}$ \\
\hline Outros Controles ${ }^{4}$ & $\operatorname{Sim}$ & Sim & Sim & Sim & Sim & Sim & Sim \\
\hline \multirow[t]{2}{*}{ Constante } & 416,32 & 430,555 & 444,394 & 461,330 & 474,914 & 489,635 & 507,260 \\
\hline & $(100,70)^{* *}$ & $(116,51)^{* *}$ & $(130,29)^{* *}$ & $(122,82)^{* *}$ & $(129,69)^{* *}$ & $(117,65)^{* *}$ & $(116,11)^{* *}$ \\
\hline Observações & 24.950 & 24.950 & 24.950 & 24.950 & 24.950 & 24.950 & 24.950 \\
\hline
\end{tabular}

Nota: O modelo inclui uma constante; as estatísticas t estão entre parênteses; * indica significância em nível de confiança de 95\% ( $p<$ 0,05) e ** significância em nível de confiança de 99\% ( $p<0,01)$.

Fonte: Dados da pesquisa (2012).

\footnotetext{
${ }^{4}$ Além das variáveis apresentadas, o modelo ainda foi controlado para as seguintes variáveis: gênero, idade, etnia, acesso à internet, hábitos de leitura, educação da mãe, se fez ensino supletivo, religião, se trabalha, só estudante,
} 
A variável Argumento de Inclusão mostra-se crescente (em módulo) e significativa em todos os quantis. Os candidatos que receberam o AI e tiveram Argumentos Parciais (argfase1) mais elevados, mesmo com todas as variáveis controle (exceto tipo de escola onde cursou o ensino médio), têm notas, em média, 23,312 pontos inferior às notas dos candidatos que estão posicionados no mesmo quantil e não recebem o benefício do AI.

A diferença entre as notas dos candidatos com e sem AI aumenta sua magnitude conforme se move do menor ao maior quantil; ou seja, os "melhores" alunos entre aqueles que são beneficiários do AI tiram notas bem inferiores às dos "melhores" alunos não beneficiários do AI. Essa diferença é menor quando estamos comparando os alunos com notas mais baixas. Esse resultado não pode ser visualizado na regressão MQO.

\section{Figura 1}

Estimativa da Regressão Quantílica para a variável c_ai (candidatos que recebem o Argumento de Inclusão)

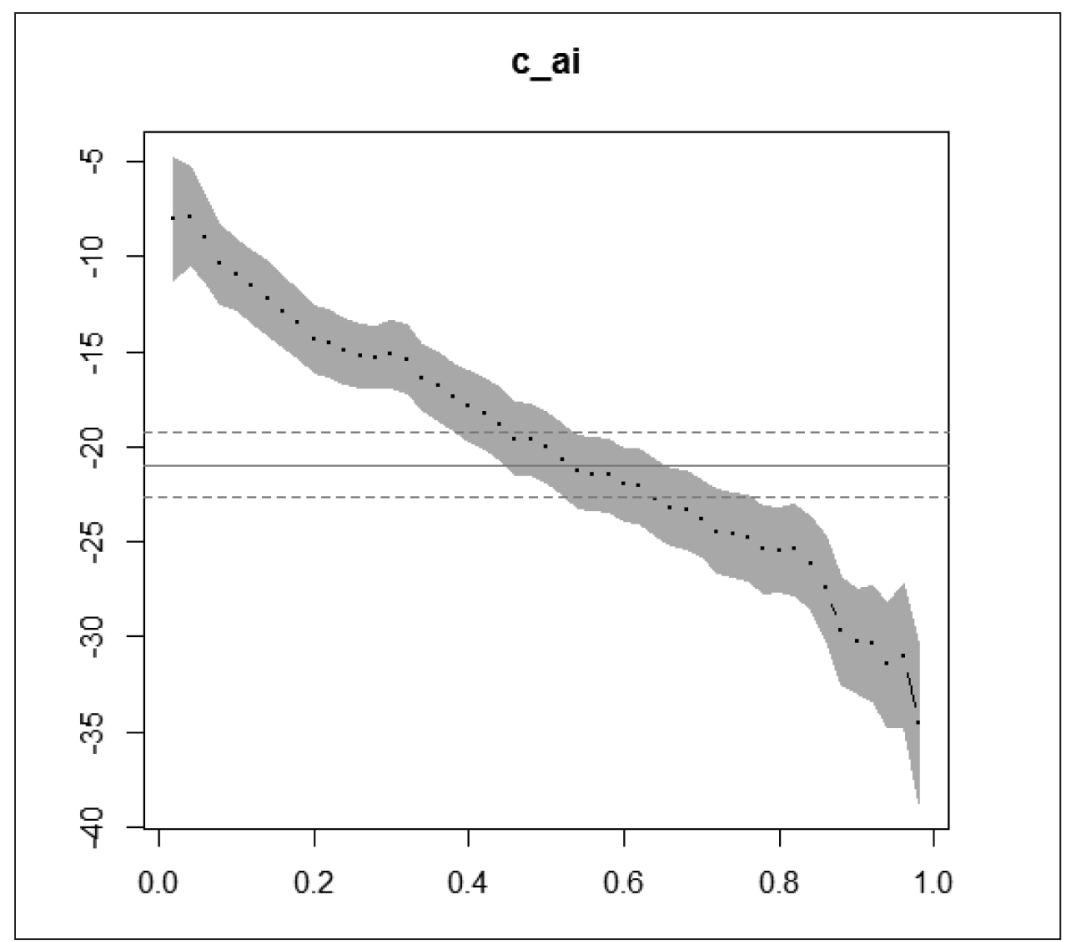

Nota: A linha pontilhada preta corresponde à estimativa quantílica, a área sombreada corresponde ao intervalo de confiança e a linha sólida representa a estimativa da regressão MQO. Fonte: Dados da pesquisa (2012).

turno, já prestou vestibular, já ingressou na universidade, nota do Enem, áreas, estado civil, tamanho da família e se mora com os pais - assim como na 3a Regressão MQO, anteriormente apresentada. 
Outra variável que deve ser ressaltada é a renda familiar. Como se está trabalhando com cinco variáveis para faixa de renda, utilizando-se a renda familiar 2 como referência, observa-se que a variável renda familiar 1 reduz de -6,52 para -13,18 conforme nos movemos do quantil mais baixo para o mais elevado da distribuição condicional. As demais faixas de renda (3, 4 e 5), assim como na regressão MQO, mostram, gradativamente, notas superiores àquelas comparadas aos candidatos com renda familiar 2.

\section{Figura 2}

\section{Estimativa da Regressão Quantílica para as variáveis de renda familiar}

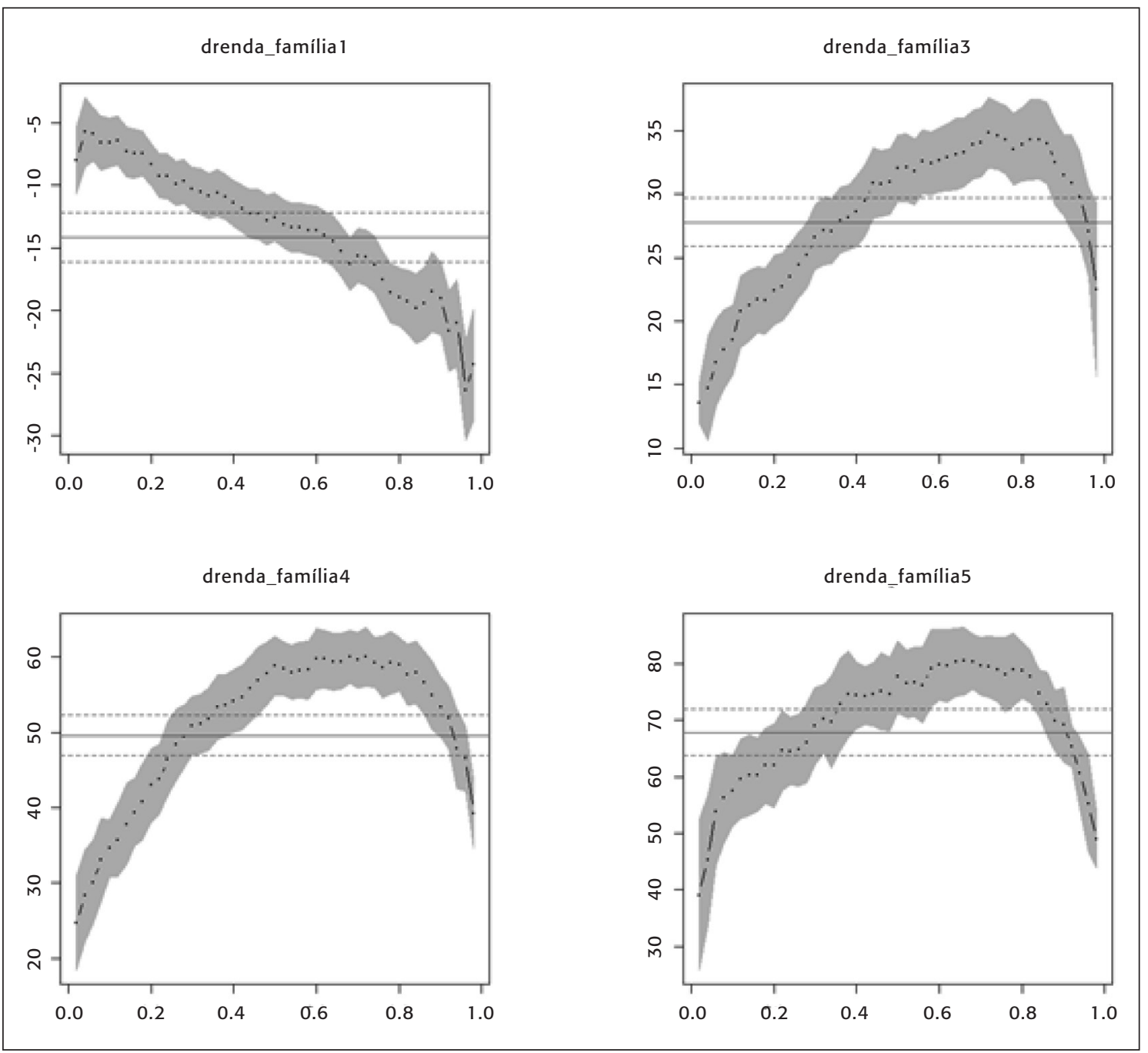

Fonte: Dados da pesquisa, 2012. 
Observa-se que os resultados, de modo geral, são próximos aos apresentados na Regressão MQO. Como o resultado da Regressão Quantílica costuma ser mais robusto, em resposta aos outliers, pode-se dizer que esses resultados reafirmam os resultados da Regressão Simples e nos permitem, ainda, algumas análises e comparativos mais aprofundados, que não podem ser observados quando utilizamos uma média única para todo o grupo.

\section{Conclusão}

Esta pesquisa tem o enfoque principal de discutir a política pública de incentivo ao ingresso de estudantes de escolas públicas na Universidade Federal do Rio Grande do Norte. Isto se faz a partir da análise do perfil dos candidatos e dos principais determinantes de acesso à universidade utilizando-se de informações referentes às notas dos candidatos no teste, assim como suas características pessoais, familiar e sua origem escolar.

Através de uma regressão usando a técnica dos Mínimos Quadrados Ordinários, reforçada por uma Regressão Quantílica, alguns resultados puderam ser observados. De um modo geral, os resultados encontrados parecem em consonância com a literatura que trata sobre o tema.

Enquanto não foram incluídos os controles para tipo de escola onde o candidato cursou o Ensino Médio, o impacto do Argumento de Inclusão mostrou-se bastante significativo, o que mostra que, ao visualizarmos os dados em conjunto, enquanto médias, os candidatos que recebem o AI têm desempenho inferior aos candidatos que não recebem o benefício. Na Regressão Quantílica o resultado se confirma, o AI mostra-se significante e crescente (em módulo) conforme aumentam os quantis, o que mostra que a diferença da nota dos alunos beneficiários e não beneficiários do AI que se encontram nos maiores percentis é bem superior à mesma comparação dos candidatos com menores notas. O fato de o candidato receber ou não o benefício do AI não apresenta grande impacto no momento em que essa variável é totalmente controlada (inclusive com controles que determinam esta política, como o tipo de escola de origem); no entanto, apesar de pequeno, ainda se apresenta significante.

As alterações na política do AI mostram que existe uma busca por um aprimoramento na política para reduzir as desigualdades sociais, mas não se enxerga um real movimento que permita igualdade escolar para se extinguir as diferenças e, consequentemente, a política de incentivos.

Em conformidade ao que se apresenta na literatura correlata, os resultados apresentados confirmam que os alunos que frequentam o ensino público tendem a ter resultados inferiores no vestibular quando comparados àqueles oriundos do ensino privado. Mas o ensino médio/técnico do IFRN, apesar de público, foge a essa regra, apresentando um diferencial bastante representativo.

Mesmo com diversos controles, assim como em outros estudos afins, a renda também se mostra bastante significante no desempenho dos candidatos. A educação da mãe também impacta positivamente os resultados dos estudantes que fazem o exame. A idade, por sua vez, influencia negativamente o resultado do vestibular. 
É possível afirmar que as características pessoais, da família e educação são determinantes nas realizações dos alunos. No entanto, o modelo aplicado não permite mensurar ou controlar fatores como motivação e habilidade. Levando-se em consideração que a primeira seleção já se faz no momento em que muitos estudantes nem se inscrevem para o vestibular, seja por impossibilidade ou por falta de perspectiva acadêmica. Pesquisas futuras devem trabalhar no sentido de estimar esses efeitos não observados.

Este trabalho abre campo para se estudar os impactos das mudanças nas regras da política do AI durante os anos. Também para um estudo dos alunos que entram e os que deixam de entrar devido à política do AI, por meio de uma análise aprofundada do grupo de alunos que está no limite das vagas. Ou, ainda, para um diagnóstico dos alunos beneficiários do AI uma vez ingressos na universidade.

\section{Referências}

ALMEIDA, Maria H. T.; CARNEIRO, Leandro P. Liderança local, democracia e políticas públicas no Brasil. Opinião Pública, Campinas, v. 9, n. 1, p. 124-147, 2003.

ALON, Sigal; TIENDA, Marta. Diversity, opportunity, and the shifting meritocracy in higher education. American Sociological Review, v. 72, p. 487-511, 2007.

AMARAL, Shirlena C. S.; RIBEIRO, Adelia M. M. A política de cotas e o acesso do negro à universidade pública: discursos e ideologias em confronto na comunidade científica, poder público e movimento social - o caso da Uenf. Confluenze: revista di studi iberoamericani, Bolonha, v. 1, n. 2, p. 227-243, 2009.

BASANT, Rakesh; SEN, Gitanjali. Parental education as a criterion for affirmative action in higher education. World Development, v. 64, p. 803-814, 2014.

BOLLINGER, Lee C. The need for diversity in higher education. Academic Medicine, v. 78, n. 5, p. 431-436, 2003.

BONAMINO, Alicia Maria C. O público e o privado na educação brasileira, inovações e tendências a partir dos anos de 1980. Dossiê: O Público e o Privado na Educação Brasileira. Revista Brasileira de História da Educação, Campinas, v. 3, n. 1 [5], p. 253-276, 2003.

CAVALCANTI, Tiago; GUIMARAES, Juliana; SAMPAIO, B. Barriers to skill acquisition in Brazil: public and private school students performance in a public university entrance exam. The Quarterly Review of Economics and Finance, v. 50, n. 4, p. 395-407, 2010.

COMPERVE. Comissão Permanente do Vestibular. Política de acesso à UFRN: estudo e proposições. Natal, 2004. Disponível em: <www.comperve.ufrn.br/conteudo/observatorio/arquivos/documentos_institucionais/politica_acesso_UFRN.pdf > . Acesso em: 10 fev. 2012.

EDITAL VESTIBULAR 2010. Disponível em: <www.comperve.ufrn.br/conteudo/psanteriores/ ps2010/edital.php> . Acesso em: 28 out. 2014. 
EMILIO, Daulins R.; ALVES, Denisard C. O.; BELUZZO Jr., Walter. Uma análise econométrica dos determinantes do acesso à Universidade de São Paulo. Pesquisa e Planejamento Econômico, Rio de Janeiro, v. 55, n. 2, p. 275-306, 2004.

FRANCIS, Andrew; TANNURI-PIANTA, Maria de Eduarda. Using Brazil's racial continuum to examine the short-term effects of affirmative action in Higher Education. In: ENCONTRO BRASILEIRO DE ECONOMETRIA, XXXI, 2009, Foz do Iguaçu.

GONÇALVES, Maria E. et al. Fatores determinantes da qualidade do ensino nas escolas de Minas Gerais: uma análise para a quarta série do Ensino Fundamental. In: ENCONTRO NACIONAL DE ESTUDOS POPULACIONAIS, XXVII, 2010, Caxambu.

GUIMARÃES, Daniel B.; ARRAES, Ronaldo A. Status socioeconômico, background familiar, formação educacional e as chances de sucesso dos candidatos ao vestibular da UFC. In: ECONOMIA DO CEARÁ EM DEBATE, IV, 2008, Fortaleza.

GUIMARÃES, Juliana; SAMPAIO, Breno. The influence of family background and individual characteristics on entrance tests scores of Brazilian university students. In: ENCONTRO NACIONAL DE ECNOMIA - ANPEC, XXXV, 2007, Recife.

GUJARATI, Damodar N.; PORTER, Dawn C. Econometria básica. 5. ed. Porto Alegre: AMGH, 2011.

GURIN, P. et al. Diversity and higher education: theory and impact on educational outcomes. Harvard Educational Review, v. 72, n. 3, p. 330-366, 2002.

INEP. Censos da educação superior brasileira. 2009. Disponível em: < http://portal.inep.gov.br/ superior-censosuperior-sinopse >. Acesso em: 30 out. 2014.

INEP. Censos da educação superior brasileira. 2013. Disponível em: <http://portal.inep.gov.br/ basica-censo-escolar-sinopse-sinopse >. Acesso em: 30 out. 2014.

MAGGIE, Yvonne. Graduação e pós-graduação nas ciências humanas no Brasil: desafios e perspectivas. In: CAPES. Discussão da pós-graduação brasileira. Brasília: Editora UNB, 1996. p. 19-28.

MAGGIE, Yvonne; FRY, Peter. A reserva de vagas para negros nas universidades brasileiras. Estudos Avançados [online], v. 18, n. 50, p. 67-80, 2004.

MAGGIE, Yvonne; FRY, Peter. Política social de alto risco. O Globo, Rio de Janeiro, 11 abr. 2006.

MAIA, Luciano M. Minorias: retratos do Brasil de hoje. DHnet. Disponível em: <www.dhnet.org. br/direitos/militantes/lucianomaia/luciano102.html>. Acesso em: 18 nov. 2014.

MOEHLECKE, Sabrina. Ação afirmativa: história e debates no Brasil. Cadernos de Pesquisa (Fundação Carlos Chagas), São Paulo, n. 117, p. 197-218, 2002.

PERIA, Michelle. Ação afirmativa: um estudo sobre a reserva de vagas para negros nas universidades públicas brasileiras. O caso do estado do Rio de Janeiro. Dissertação (mestrado) — Programa de PósGraduação em Antropologia Social, Universidade Federal do Rio de Janeiro, Rio de Janeiro, 2004.

PRADO, Berenice S. do. O ingresso no ensino superior público de egressos da educação básica pública: o sistema de cotas na Universidade Federal do Paraná. Dissertação (mestrado) — Universidade Federal de Santa Catarina, Florianópolis, 2008. 
QUEIROZ, Delcele M. Desigualdade no ensino superior: cor, status e desempenho. REUNIÃO DA ANPED, NOVO GOVERNO. NOVAS POLÍTICAS?, 27., 2003, Caxambu.

QUEIROZ, Delcele M. Sistema de cotas: um debate. Dos dados à manutenção de privilégios e de poder. Educação \& Sociedade, Campinas, v. 27, n. 96, p. 717-737, 2006.

ROSA, Alexandre R. Relações raciais e estudos organizacionais no Brasil. RAC, Curitiba, v. 18, n. 3, p. 240-260, 2014.

SAMPAIO, Breno; GUIMARAES, Juliana. Diferenças de eficiência entre ensino público e privado no Brasil. Revista Economia Aplicada, Ribeirão Preto, v. 13, n. 1, p. 45-68, 2009.

SITE COMPERVE. Argumento de Inclusão 2006. Disponível em: <www.comperve.ufrn.br/conteudo/ psanteriores/ps2006/argumentoinclusao.htm>. Acesso em: 28 out. 2014.

VILLENAVE, Baptiste. La discrimination positive: une presentation. 2006. Disponível em: <www. eleves.ens.fr/pollens/seminaire/seances/discrimination/synthesediscrimination.htm > . Acesso em: 5 nov. 2014.

WHITLA, Dean K. et al. Educational benefits of diversity in medical school: a survey of students. Academic Medicine, v. 78, n. 5, p. 460-466, 2003.

Almog Griner é doutoranda em administração pela Universidade Federal do Rio Grande do Sul (UFRGS) na área de estudos organizacionais. E-mail: almogadm@gmail.com.

Luciano Menezes Bezerra Sampaio tem pós-doutorado em economia na University of Illinois, é doutor em economia pela Universidade Federal de Pernambuco (UFPE) e professor do Departamento e Pósgraduação em Administração da Universidade Federal do Rio Grande do Norte (UFRN). E-mail: luciano. sampaio@pq.cnpq.br.

Raquel Menezes Bezerra Sampaio é doutora em economia pela universidade de Toulouse e professora da Escola de Ciências e Tecnologia da Universidade Federal do Rio Grande do Norte (UFRN). E-mail: raquelmbsampaio@gmail.com. 